\title{
Food Geographies, Some Considerations in the Current Research
}

\section{Trends}

\begin{abstract}
Mazorra AP*
Institute of Policies and Public Goods, Department of Economics and Policy Group, Spain
\end{abstract}

*Corresponding author: Angel Paniagua Mazorra, Institute of Policies and Public Goods, Department of Economics and Policy Group, Scientific Researcher of OPIS, Spain, Tel: (+34) 916022546; Email: angel.paniagua@cchs.csic.es

\section{Editorial}

Food geographies are a remarkable way of progress in rural studies and also in food studies. They provide a spatial dimension, which can be understood as approach or as a subject of study, the traditional geography of food, which tries to describe the geographical distribution of food consumption production. In this reflection we chose to consider food geographies as a renewed approach to both rural geography and the place.

It is necessary to place the value of current trends in food geographies, in the evolution of trends in agricultural geography:

1. In traditional agricultural geography, which lasts until the mid-1980s, is based on the description and explanation of spatial variations in agricultural activities on the land surface. This orientation had two essential tendencies, on the one hand the location and description of the relational context of the characteristics of agricultural activities and the interaction between the factors of food production, on the other hand the explanation of the diversity of agrarian systems at a global level.

2. Behavioral approaches, a trend that took off at the beginning of the 1980s, associated with a certain positivism, to describe and analyze the characteristics and 'quality' of each individual farmer. There is a humanistic concern for the individual identity of the farmer. This tendency also to finding studies on the adoption of innovations by the farmer.
3. Political economy approaches. This orientation began in the mid-1980s. The agricultural exploitation is analyzed as a piece between two poles of social relations, the global pole and the local pole. Emphasis is placed on the relevant role of the State, the economy and power relations. This suggests a complex agenda associated with four axes: the unequal development, the geographical and historical specificity of the geographic location, the conceptualization of the family farm and, finally, the relationships between agriculture and state policies.

4. New trends to explain agrarian change: (a) Food regimes, a trend that combines the geography of agriculture and the political economy. It considers together the geography of production and the geography of food, as two sides of a binomial. The food regimes constitute a context to adequately analyze trajectories of local change. (b) Food regulatory theories. They emphasize the interpretation and formulation of legal regulation and the agrarian and food politics that surround them. (c) Agrarian question. It is the most common option among geographers who move in the perspective of the political economy. It presents a remarkable analytical preoccupation by the specificity and resistance of the familiar exploitations, under the influence of the work of Kalesky's.

The sociocultural turn of rural geography influences food geographies. This orientation supposes an approach to the constructivist currents of the social reality, applied to the place and, in general, the space. It also implies the 


\section{Food Science and Nutrition Technology}

emergence of a new agenda, which will be applied to food geograhies.

This new agenda affects:

1. Nature-society relations, including landscape perceptions associated with food, meaning of nature and food in the constitution of rurality and human-nonhuman relations in the production and consumption of food.

2. Discourses on particular experiences in the production of food, images of foods associated with places. Studies on other rural or alternative lives based on alternative food productions.

3. Symbolic texts about traditional food cultures, or representations of foods in mass media or their contribution of food to the reproduction of discourses on rurality.

4. Social movements and food, including different aspects of alternative populations or neo nomads and food production.
From what has been pointed out so far, the remarkable continuity of food geographies can be deduced, with different labels or orientations and its analytical value in the socio-spatial dimension of food science.

As future trends, it is possible to indicate some orientations that will have remarkable value within the food geographies: (1) the alternative food geographies, associated with the geographical proximity and the ecological and post-organic food productions. (2) A new revalorization of the geographical rural place(s), as differentiated place(s) of food productions. (3) The cultures of geographical place food production, associated with the new identities of the place. (4) The geographical food as an element of resistance of the place.

In definitive, a great role (and future) of the food geographies in the food science. 